\title{
DIFICULDADES ATUAIS DO SISTEMA INTERNACIONAL DE DIREITOS HUMANOS
}

\section{DIFICULTADES ACTUALES DEL SISTEMA INTERNACIONAL DE DERECHOS HUMANOS}

José Augusto Lindgren-Alves*

Resumo: Os direitos humanos, depois de atingir o ponto culminante de popularidade na Conferência de Viena de 1993, entraram numa fase de descrédito, que ainda perdura. Isso ocorreu por diversos motivos, alguns dos quais interiores ao próprio sistema estabelecido para promovê-los. Os principais fatores decorrem da contradição entre a asserção verbal dos direitos fundamentais de todos e o "consenso" neoliberal simultaneamente imposto na esfera econômica. Outros são inerentes ao ativismo fragmentário, sem noção de causa e efeito, desvinculado da realidade circundante. Os problemas do segundo tipo são passíveis de correção, se para isso houver coerência e destemor de críticas nas atitudes dos atores influentes. O texto examina os componentes desse sistema internacional e identifica as razoes de sua atual desvalorização.

Resumen: Los derechos humanos, después de alzcanzar el punto culminante de popularidad en la Conferencia de Viena de 1993, entraron en uma fase de descrédito, que aún perdura. Eso ocurrió por varios motivos, algunos de los cuales están al interior del propio sistema estabelecido para promocionarlos. Los factores principales advienen de la contradicción entre la aserción verbal de los derechos fundamentales de todos y el "consenso" neoliberal simultaneamente impuesto a la esfera económica. Otros son inherentes al activismo fragmentario, sin noción de causa y efecto, desvinculado de la realidad en vuelta. Los problemas de segundo tipo son corregibles si para eso hubiese coherencia y destemor de críticas en las atitudes de los actores

\footnotetext{
* Instituto de Políticas Públicas de Direitos Humanos do MERCOSUL, Argentina.

E-mail: lindgrenja@aol.com

Tradução ampliada de texto em espanhol, utilizado em curso sobre "Conflictos Actuales y Cooperación Internacional", dentro do tema "Construcción de la Paz, Derechos Humanos y Cooperación Internacional", na Universidade de Barcelona, em 2014. No formato original, foi publicado na Monções: Revista de Relações Internacionais da UFGD, vol 3, no 6, 2014. No presente formato, comporá o segundo capítulo de livro do mesmo Autor, intitulado É Preciso Salvar os Direitos Humanos!, a ser publicado pela Editora Perspectiva, em São Paulo, ainda em 2017.

Recibido: 26/06/2017. Aceptado: 01/09/2017.
} 
influyentes. El texto examina los componientes de ese sistema internacional $e$ identifica las razones de su presente desvaluación.

Palavras-chave: Direitos humanos, Instrumentos e mecanismos, universalismo, Igualdade, Minorias

Palabras clave: Derechos humanos, Instrumentos y mecanismos, universalismo, Igualdad, Minorías

\section{ESCLARECIMENTO PRÉVIO}

O presente texto, voltado para o sistema existente no âmbito das Naçoes Unidas, reflete uma experiência de trinta anos, como delegado ou perito independente, em vários de seus órgãos. Não se refere ao sistema interamericano, nem a instituições do MERCOSUL, área em que não passo de principiante. A matéria, geralmente divulgada do ponto de vista jurídico e aqui tratada com enfoque político, não apologético, deve ser de interesse também hemisférico. Concordando-se ou não com as interpretações expostas, os instrumentos, mecanismos e tendências precisam ser conhecidos por todos os que trabalham em prol dos direitos humanos. As dificuldades atuais focalizadas são aquelas hoje magnificadas inconscientemente pelos próprios agentes do sistema. O objetivo do estudo é pragmático: tratando de problemas momentaneamente "culturais", de uma vertente do discurso ocidental, dominante, mas não consolidada, eles me parecem mais fáceis de resolver dentro do sistema do que as dificuldades advindas de fatores estruturais que o extrapolam. O primeiro passo para isso é, portanto, conhecê-los.

\section{O SISTEMA INTERNACIONAL DE DIREITOS HUMANOS STRICTO SENSU E OS DEMAIS}

O sistema internacional de promoção e proteção aos direitos humanos foi criado pouco a pouco, depois da Segunda Guerra Mundial, para tratar dos direitos e liberdades fundamentais de todos os seres humanos em tempos de paz. Se não fosse assim, constituiria um disparate o fato de o artigo $4^{\circ}$ do Pacto sobre Direitos Civis e Políticos estabelecer um procedimento formal a ser cumprido pelos Estados-partes para suspensão das respectivas obrigações "quando situações excepcionais ameacem a existência da Nação e sejam oficialmente proclamadas”. A par dessa previsão de suspensão de direitos em "estados de emergência", legalmente declarados e comunicados pelos governos a seus pares por intermédio do Secretário Geral da ONU, o conteúdo de quase todos os artigos desse tratado e a fortiori do Pacto sobre Direitos Econômicos, Sociais e Culturais afigura-se obviamente irrealista em tempos de guerra. Essa qualificação do sistema, que ressalto em primeiro lugar, costuma passar 
despercebida por juristas, militantes e acadêmicos dedicados ao assunto.

Antes mesmo de serem listados e proclamados em documento da nova Organização, os direitos humanos, então ainda imprecisos, foram incluídos entre as áreas de cooperação a cargo do Conselho Econômico e Social (ECOSOC), nos artigos 55 e 56 da Carta das Nações Unidas, adotada no final da Conferência de São Francisco, em 26 de junho de 1945. Diante dos horrores perpetrados pelo nazi-fascismo antes e durante a Segunda Guerra Mundial, os direitos fundamentais de todas as pessoas eram vistos não somente por seu valor intrínseco, de atributos essenciais à vida e à sobrevivência condigna de qualquer ser humano, mas também e sobretudo por seu valor preventivo contra a irrupção de novas guerras.

Os direitos humanos nunca foram, portanto, e por natureza não podem ser, instrumentos para acabar com conflitos bélicos. Sejam eles guerras entre Estados, ou de caráter dito "civil", entre governos e tropas armadas insurgentes ou entre facções que se digladiam num mesmo território - não confundir com os grupos de idealistas "revolucionários" contra as ditaduras dos anos 1960 a 80, que nunca chegaram a constituir risco efetivo para "a Nação". Para lidar com ameaças militares à paz e à estabilidade internacional as Nações Unidas estabeleceram o Conselho de Segurança, de composição especial, com cinco membros permanentes e outros temporários, que nunca fez parte do sistema regular de direitos humanos. Até hoje, em princípio, a ação do Conselho de Segurança na matéria constitui recurso extraordinário.

Tendo esse lembrete como ponto de partida, o sistema internacional de promoção e proteção dos direitos humanos stricto sensu, de que trato, poderia ser definido como o conjunto de regras e mecanismos de supervisão estabelecidos pelos órgãos competentes das Nações Unidas desde que a Assembleia Geral proclamou, em 10 de dezembro de 1948, a Declaração Universal dos Direitos Humanos. A finalidade desse sistema seria garantir, com normas negociadas e outras iniciativas legítimas, sem recurso a intervenções pela força, ou a "operações de paz", de composição policial e militar, a observância por todos os Estados dos direitos nela consagrados ${ }^{1}$.

Aqui sou levado a fazer outra precisão. É indiscutível que o novo ramo do Direito conhecido como Direito Internacional dos Direitos Humanos teve início com a Declaração Universal de 1948. Inspirados nela ou ainda nos esforços para sua preparação, há sistemas regionais em funcionamento no continente americano, na Europa e na África, que atuam de forma independente, dita "complementar", em paralelo ao sistema da ONU e com maior cogência jurídica. Entretanto, e isto é um

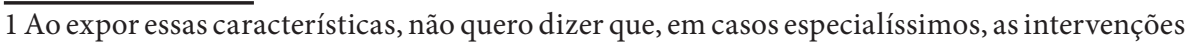
armadas com autorização do Conselho de Segiurança não sejam necessárias. Eu próprio, na época dos bombardeios de artilharia pesada servia contra Sarajevo e outras cidades sitiadas da Bósnia, de 1992 a 95, revoltava-me com a falta de ação decisiva da ONU para terminar com os massacres. 
fato significativo, a Declaração Universal, como o próprio nome indica, é único documento definidor de direitos que se propunha abranger todo o planeta, para aplicação por todos os Estados e em territórios não independentes, acima de regimes e culturas. Se essa pretensão correspondia à realidade ou a um projeto veremos depois.

Há ainda uma terceira delimitação de foco necessária. É que do ponto de vista da doutrina geralmente aceita, a disciplina do Direito Internacional dos Direitos Humanos se subdivide em dois grandes ramos: o dos direitos humanos propriamente ditos, a serem observados em qualquer situação, mas voltados para sociedades em condições, digamos, normais, e o Direito Internacional Humanitário, relacionado a situações de guerra. Os direitos humanos propriamente ditos, que idealmente valem para todas as situações, contam com onze grandes instrumentos jurídicos, ou sejam pactos e convenções, com seus protocolos adicionais e mecanismos de supervisão, e muitas outras declarações normativas específicas. É a esse conjunto que as pessoas se referem quando falam de "sistema internacional de direitos humanos". E é sobre ele que discorrerei.

O Direito Humanitário é específico e se desenvolve em dois segmentos distintos: o das Convenções de Genebra de 1949, promovidas pelo Comitê Internacional da Cruz Vermelha - CICR, especialmente o tratamento a ser dado a civis e a "prisioneiros de guerra" pelos Estados em situações de conflito, e o da Convenção de Genebra de 1951, com seu protocolo de 1967, que dá base ao Direito dos Refugiados, hoje extensivo às pessoas internamente deslocadas. Enquanto o primeiro segmento, expressão do direito na guerra, tem sido rotineiramente desconsiderado, o segundo, também contornado com frequência, torna-se particularmente relevante nos dias correntes, em função da proliferação de conflitos étnicos e religiosos, exigindo atenção e análise que ultrapassam os objetivos deste texto.

Uma vez feitos estes últimos esclarecimentos, posso adiantar que uma das dificuldades do sistema internacional dos direitos humanos na fase presente deriva da mistura teórica e prática que se faz entre os dois grandes ramos do Direito Internacional dos Direitos Humanos. Por mais que eles se complementem, não podendo um ramo ignorar o outro, a aplicabilidade de cada um e a respectiva possibilidade de implementação são totalmente diferentes. Não se podem comparar exageros no controle da criminalidade, a repressão de opositores ou a não realização dos direitos econômicos e sociais num país em situação de paz com as ações bélicas e inações de governos e insurgentes em conflito armado desencadeado ${ }^{2}$.

2 Reitero aqui a ideia de "conflito armado desencadeado" para evitar confusão com rótulos empregados por governos arbitrários contra opositores civis. Usando expressões como "guerra suja", "inimigo interno", "subversão da ordem" etc., os regimes militares da América 
A mescla desses ramos, compreensível, ocorre por iniciativa do próprio Conselho - antes Comissão - dos Direitos Humanos. Especialmente desde que o(a) Alto(a) Comissário(a) das Nações Unidas para os Direitos Humanos, cargo político-administrativo de status indefinido no Secretariado, passou a participar das reuniões mais delicadas do Conselho de Segurança, no início do Século XXI ${ }^{3}$. No afã justificado de demonstrar interesse e buscar algum alívio para populações civis e prisioneiros em posição desesperadora em meio a embates bélicos, o atual Conselho de Direitos Humanos e o Alto Comissário tentam agir. Tal tentativa sempre foi recomendada e feita, com menos assiduidade do que agora, até porque o número de conflitos armados era menor. Os órgãos do sistema de direitos humanos stricto sensu não têm, contudo, meios para ir além do que fazem em outras situações: criam comissões de inquérito; estabelecem, quando podem, monitores para atuar in loco; apelam para a consciência ética das partes, da opinião pública, das ONGs e do conjunto da comunidade de Estados.

É evidente que tais iniciativas não têm efeito moral perceptível junto a quem já optou pela violência estratégica, trate-se de governos, forças insurgentes ou, menos ainda, facções religiosas extremadas ou organizações terroristas. Por mais convincentes que os informes e análises dos inspetores designados se apresentem, a tendência é permanecerem inócuas entre as partes em conflito e entre os membros permanentes do Conselho de Segurança ${ }^{4}$.

\section{EVOLUÇÃO DO SISTEMA ATÉ O FIM DA GUERRA FRIA}

Sem maior aprofundamento de ideias doutrinárias, filosóficas e religiosas que fundamentam a concepção dos direitos humanos como categoria dos direitos sem os quais a vida de qualquer pessoa se torna indigna ou impossível, a história factual do estabelecimento do sistema internacional para sua promoção e proteção nas Nações Unidas é bastante conhecida. Pode, ou podia antes, ser resumida em

\footnotetext{
Latina pretendiam justificar suas práticas violatórias de direitos humanos dos cidadãos. Não tiveram êxito. Como veremos adiante, foram suas ações tenebrosas que levaram a ONU a criar mecanismos de observação de situações e temas.

3 Anotei esse fato relevante ao ler a excelente tese de doutorado do Professor Matheus de Carvalho Hernandez, sobre o papel crescentemente protagônico do Alto Comissariado das Nações Unidas para os Direitos Humanos (O Alto Comissariado das Nações Unidas para os Direitos Humanos e seu Escritório: Criação e Desenvolvimento Institucional, defendida na UNICAMP, Campinas, 2015 - texto digitalizado).

4 Ao escrever estas linhas, penso nos excelentes informes apresentados há anos pelo Professor Paulo Sergio Pinheiro, na qualidade de presidente da comissão de inquérito independente sobre a Síria. Se tivessem sido levados em consideração pelos atores de fora, teriam evitado a continuação dos fluxos de ajuda a grupos insurgentes e a excessos repressivos do Governo, todos responsáveis pela prolongação absurda da guerra. Teriam, inclusive, estancado fontes de armamentos que vão parar nas mãos do "Estado Islâmico" ou ISIS, que todos temem, e alguns utilizam.
} 
termos políticos como o resultado da eterna disputa entre as noções de intervenção e de soberania.

Todos os interessados na matéria sabem das tradicionais reservas dos Estados à possibilidade de acompanhamento internacional de suas situações, de seu rechaço peremptório à ideia de supervisão externa, vista como violação ao atributo da soberania e ao princípio da não intervenção em assuntos internos. Tal princípio jurídico sempre foi base da doutrina das relações internacionais desde o fim da chamada Guerra dos Trinta Anos, havendo fundamentado os célebres Tratados de Paz de Westfália, que acabaram com as guerras de religião na Europa do Século XVII. Tal princípio se acha consagrado no artigo $2^{\circ}$, Parágrafo $7^{\circ}$, da Carta das Nações Unidas, de 1945, como essencial para o funcionamento da Organização que se então se estabalecia. Precisamente porque a noção de soberania estatal correspondia a uma necessidade histórica de séculos, o sistema de proteção aos direitos humanos sempre enfrentou dificuldades para sua superação.

A desconfiança com relação a tudo o que pudesse atentar contra a noção de soberania estatal sempre foi tão forte que, até a década de 1970, a antiga Comissão dos Direitos Humanos das Nações Unidas, órgão subsidiário do Conselho Econômico e Social com mandato para tratar de temas dos direitos humanos, não se permitia emitir opiniões sobre queixas de violações levadas a seu conhecimento. Pouco a pouco, porém, essa autolimitação de competência da Comissão foi sendo ultrapassada. Desde os anos 1970, em particular diante da situação dos habitantes de territórios árabes ocupados por Israel e dos absurdos, conhecidos e denunciados internacionalmente, do regime constitucional do apartheid na África do Sul, a Comissão dos Direitos Humanos decidiu acolher as comunicações das respectivas vítimas, examiná-las e fazer recomendações contra a violação sistemática de direitos humanos nesses países e territórios. Tal tipo de atividade se tornou mais incisiva, exercendo pressão moral sobre os respectivos governos em qualquer situação nacional, depois que a Assembleia Geral, em 1975, supostamente chocada com as violações de direitos humanos no Chile na época do General Pinochet, decidiu estabelecer um Grupo de Trabalho para acompanhar o caso. Essa decisão inédita constituiu o precedente para resoluções que designavam relatores especiais para outras situações, assim como um Grupo de Trabalho para examinar, com base em testemunhos e informações de fontes variadas, o fenômeno dos "desaparecimentos" de pessoas em países de regime militar na América Latina. Daí em diante foi crescendo o número de relatores criados pela Comissão e pela Assembleia Geral para acompanhar e descrever, com recomendações, as situações prevalecentes em alguns Estados, donde seu título informal de "relatores de situações", e para analisar determinados fenômenos em todo o mundo, os chamados "relatores temáticos". Todos 
eles, assim como os integrantes de grupos de trabalho equivalentes, são funções exercidas por personalidades selecionadas para atuar na qualidade de especialistas imparciais.

É evidente que os cargos de relatores de situações, mais do que os temáticos, eram propostos para Estados do campo adversário, e os relatores somente podiam ser designados por resoluções dos órgãos competentes quando as diferentes posições de grupos e países não impediam o andamento dos projetos e sua aprovação, quase sempre por voto. Conquanto essa "seletividade" tenha existido desde os primórdios do sistema, acirrada em função dos antagonismos ideológicos e blocos estratégicos do período de Guerra Fria, não se tendo nunca designado relator para país violador, de direita ou de esquerda, protegido por aliados, isso não impediu que a inovação se consolidasse como mecanismo expressivo para a proteção internacional dos direitos humanos.

Até o final dos anos 1980, o sistema internacional de promoção e proteção dos direitos humanos em sentido estrito tinha, com seus defeitos e virtudes, como órgãos competentes nas Nações Unidas, além da Assembleia Geral, sua instância máxima, o Conselho Econômico e Social (ECOSOC) e a Comissão dos Direitos Humanos, a ele subordinada, que se reunia regularmente em Genebra 45 dias ao ano. Todos eram órgãos compostos por Estados. A Comissão, por sua vez, contava com um órgão técnico subsidiário, sui generis em diversos aspectos: a Subcomissão para Prevenção da Discriminação e Proteção de Minorias. Encarregada de realizar estudos e fazer propostas, inclusive de novas normas, à Comissão, a Subcomissão era integrada por "peritos", indicados como candidatos pelos Estados-membros da ONU, mas eleitos pela Comissão para atuar sem representar os países respectivos. Além da composição atípica, o órgão tinha nome não apenas longo, mas surpreendente, pois não havia definição acordada para o termo "minoria" .

Era de todos esses órgãos, especialmente da Comissão dos Direitos Humanos, cujas sessões anuais atraíam jornalistas e as poucas ONGs atuantes, que emanavam as resoluções sobre situações, amplamente divulgadas como moções de condenação da ONU aos governos em questão. Essas resoluções, vistas como manifestações internacionais capazes de constranger os governantes envolvidos a modificar suas práticas, gozavam de ampla popularidade. E é inegável que esse tipo de pressão, estritamente moral, sem violar as soberanias, aos poucos gerava resultados positivos junto a governos preocupados com sua imagem. Levavam, por exemplo, em países da América Latina, com governos militares ditos defensores da democracia contra o comunismo, a um maior controle sobre as forças de repressão, reduzindo os casos de torturas e desaparecimentos, permitindo maior liberdade de expressão

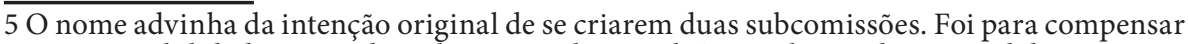
sua inexequibilidade que os dois objetivos nele se incluíram - barganha em prol do consenso. 
artística, e assim por diante. Respaldando anseios domésticos sufocados, essas pressões foram importantes na promoção de aberturas políticas, anistias e libertação de opositores presos. Dentro dessa mesma lógica, de preocupação com a imagem externa, governos arbitrários moralmente acuados, depois de resistências iniciais, frequentemente acabavam por aceitar visitas dos relatores designados para sua situação, dialogando e cooperando com eles.

Os relatores temáticos, cujo mandato não consistia em examinar países determinados, mas sim violações de direitos selecionados em qualquer parte do mundo, eram poucos e muito respeitados. Os mais conhecidos eram o Grupo de Trabalho sobre Desaparecimentos Forçados ou Involuntários, o Relator sobre Execuções Sumárias e Arbitrárias e o Relator sobre a Tortura. Aos poucos se foram acrescentando outros, sobre liberdade de religião, violência contra a mulher etc. Não obstante, até o final dos anos 1980 o total não era mais do que sete ou oito, o que habilitava a leitura atenta de seus informes e recomendações. A renovação de seus mandatos pela Comissão era assunto sensível, que gerava discussões acirradas dos delegados de Estados com base na análise de seus textos.

Menos conhecidos do público, mas seguramente mais importantes do que qualquer resolução divulgada, eram os seis tratados - dois pactos e quatro convenções - do sistema, que formavam o Direito Internacional dos Direitos Humanos. Por mais que eles constituíssem instrumentos cogentes para os subscritores, levando-se em consideração que a decisão de ratificá-los era voluntária, as limitações e obrigações normativas eram também, logicamente, autoimpostas. Não constituíam violações à soberania. Todos esses instrumentos jurídicos, por sua vez, contavam com mecanismos próprios de acompanhamento, os chamados "órgãos de tratados", comitês de peritos eleitos pelos respectivos Estados-partes, estabelecidos por estipulações do texto convencional para observar sua aplicação e fazer recomendações.

Os seis tratados vigentes no final dos anos 1980 eram:

- o Pacto Internacional sobre Direitos Civis e Políticos, de 1966

- o Pacto Internacional sobre Direitos Econômicos, Sociais e Culturais, de 1966

- a Convenção sobre a Eliminação de Todas as Formas de Discriminação Racial, de 1965

- a Convenção sobre a Eliminação de Todas as Formas de Discriminação contra a Mulher, de 1979

- a Convenção contra a Tortura e Outros Tratamentos Cruéis, Desumanos e Degradantes, de 1983

- a Convenção sobre os Direitos da Criança, de 1989. 
Esse era o quadro do sistema internacional de direitos humanos quando ocorreu a queda do Muro de Berlim, em novembro de 1989, episódio geralmente adotado como marco do fim da Guerra Fria. Interpretado por muitos como o triunfo da democracia, a vitória irreversível do Ocidente capitalista sobre o totalitarismo comunista de economia centralizada, o final da confrontação dos dois grandes blocos liderados por superpotências antagônicas, propiciou uma fase de entusiasmo pela ideia dos direitos humanos. Considerados intrínsecos à democracia liberal, passaram eles a ser vistos então, inclusive pelo público, como uma utopia realizável, num mundo sem rivalidades profundas ou ameaça de destruição pela corrida armamentista.

Foi nesse clima de euforia dominante que emergiu a ideia de convocação de uma conferência mundial sobre os direitos humanos, considerados "novo tema" que se afirmava solidamente na agenda internacional em paralelo ao do meio ambiente.

\section{A CONFERÊNCIA DE VIENA COMO PONTO CULMINANTE}

Embora entre a aprovação da proposta original, na Assembleia Geral, em fins de 1989, e a realização da Conferência, em Viena, em junho de 1993, já houvessem ocorrido mudanças no cenário demonstrativas de que o otimismo era excessivo - guerras na ex-Iugoslávia, conflitos no Cáucaso, a continuação da guerra civil em Angola, tensões étnicas agravadas em Ruanda e no Burundi, ou o terrorismo dos fundamentalistas islâmicos da Argélia -, as ONGs, a maioria dos Estados e demais atores influentes consideravam os direitos humanos uma fonte abundante de esperanças. Encaravam-nos não somente como um objetivo universal alcançável, mas também como instrumento para orientar as sociedades no rumo do progresso social. Foi essa lógica que permeou todas as grandes conferências das Nações Unidas na década de 1990. Começando pela Rio-92, sobre meio ambiente e desenvolvimento, no Rio de Janeiro, e prosseguindo em Viena, em 1993; no Cairo, em 1994, sobre população e desenvolvimento; em Copenhague, em 1995, sobre desenvolvimento social; em Pequim (Beijing), sobre a Mulher, também em 1995; em Istambul, com a Habitat-II, em 1996, sobre assentamentos humanos, todos os documentos programáticos adotados tiveram os direitos humanos como inspiração e medida de legitimação das iniciativas previstas.

A Conferência de Viena, de 1993, com sua Declaração e Programa de Ação, representou, de fato, um progresso extraordinário para a afirmação dos direitos humanos na agenda internacional, em diferentes Estados e no discurso político da época. Conquanto outras apresentações de avanços obtidos na Conferência sejam possíveis, eu os resumo em quatro pontos nunca antes observados tão claramente. São eles: 
a) a afirmação consensual da natureza universal indubitável dos direitos humanos (Par. $1^{\circ}$ da Declaração), desfazendo a impressão - engendrada a posteriori pela adoção da Declaração dita Universal em 1948, quando a maior parte da humanidade ainda se encontrava sob regime colonial - de que tais direitos eram uma imposição do Ocidente sobre o resto de mundo;

b) o reconhecimento da importância dos particularismos nacionais e regionais, que devem ser levados em conta, mas em equilíbrio com os direitos humanos, que necessitam ser respeitados (Par. $5^{\circ}$ ). Permite-se, assim, a valorização adequada das culturas não-Ocidentais, sempre que elas não atentem contra os direitos universais reconhecidos internacionalmente;

c) a reafirmação consensual dos direito ao desenvolvimento como um direito humano universal (Par. 10), que garante, mas não condiciona, a realização da igualdade e indivisibilidade de todos os direitos humanos (Par. $1^{\circ}$ e outros);

d) o reconhecimento da legitimidade da preocupação internacional com os direitos humanos, cuja promoção e proteção devem ser um objetivo prioritário das Nações Unidas (Par. $4^{\circ}$ ) objetivo que, por extensão lógica, não viola o princípio da não intervenção em assuntos internos.

Depois da adoção sem voto de tais conceitos explicativos por um conclave oficial que congregou representantes governamentais e não governamentais de praticamente todo o mundo, não cabe mais insistir na interpretação política, recorrente apenas na academia, de que os direitos humanos são uma invenção da cultura ocidental forçada sobre as demais. A insistência em tal afirmação, supostamente justificadora de práticas tradicionais violadoras de direitos, denota, ela própria, um eurocentrismo paternalista que os não ocidentais rejeitam. Como me tem sido dado observar diretamente de delegações estatais, assim como pela via de escritos importantes por teóricos de origem diversa, todas as culturas que se manifestam na matéria afirmam, ao contrário, que a adesão à ideia de tais direitos e sua observância, com adaptações, no respectivo contexto, advêm de tradições próprias, religiosas ou não ${ }^{6}$. Tampouco faz sentido dizer agora que a supervisão internacional de situações nacionais pelas Nações Unidas agride a soberania nacional e o princípio da não intervenção. Governantes que ainda o dizem, fazem-no em contradição com o que os Estados por eles governados aprovaram.

Somente por esses pontos, aprovados por todos os países de um

6 Somente lideranças religiosas fundamentalistas passaram a afirmar, mais recentemente, diante de algumas exigências liberais incorporadas ao sistema, mas não imprescidíveis para a observância da igualdade prevista na Declaração Universal, que a ideia de direitos humanos viola os direitos divinos. 
mundo já sem colônias - situação antinômica à das Nações Unidas em 1948 -, a Conferência de Viena já teria representado um divisor de águas para os direitos humanos. Ademais deles, porém, ela fez recomendações extraordináriasemseu Programade Ação, algumasdasquaisvinham sendo sugeridas sem êxito por décadas, como a proposta de estabelecimento nas Nações Unidas de um Alto Comissário para os Direitos Humanos e o apoio ao estudo da Comissão de Direito Internacional para a criação de um Tribunal Penal Internacional para crimes contra a humanidade. $\mathrm{O}$ primeiro foi estabelecido pela Assembleia Geral no mesmo ano de 1993. O Tribunal foi constituído com a aprovação de seu Estatuto em Roma, em 1998. Outras recomendações obtiveram menos resultados, como a de coordenação dos mecanismos de controle e órgãos de tratados do sistema, para evitar superposições desnecessárias e simplificar a tarefa de apresentação de relatórios pelos Estados. Com um Programa de Ação de 100 parágrafos, a Conferência fez sugestões sobre uma vasta gama de assuntos, todas destinadas a garantir os direitos universais, com atenção especial para os integrantes de grupos vulneráveis ou em posição de inferioridade social: segmentos populacionais vítimas de discriminação racial, pessoas pertencentes a minorias nacionais, étnicas, religiosas e linguísticas, populações indígenas, trabalhadores migrantes, pessoas com deficiência e, especialmente, mulheres e crianças.

É importante notar que todas as recomendações feitas em Viena sobre minorias e grupos vulneráveis eram realistas: não propunham mais do que o particularmente necessário para o gozo de direitos universais. Se algo ocorreu depois que modificou o sentido dessas recomendações, criando direitos específicos e modelos de tratamento para esses e outros grupos - e é evidente que ocorreu -, a ideia não vinha de Viena, que não inventou novos direitos para qualquer categoria. Medidas especiais para os integrantes de certos grupos em situação historicamente desvantajosa são justificadas, durante tempo limitado, para se alcançarem avanços individuais e coletivos que os equiparem à situação dos demais. Assim são elas previstas desde 1965 na Convenção sobre a Eliminação da Discriminação Racial. Recomendáveis ou necessárias, tais medidas não devem ser confundidas como novos direitos humanos - como apenas os indígenas depois passaram a ter, por declaração adotada nesse sentido pela Assembleia Geral das Naçoes Unidas em 2007.

Em termos conceituais, práticos e doutrinários, direitos específicos permanentes vão contra a essência da noção dos direitos humanos como direito fundamentais de todos. A própria Declaração dos Direitos das Pessoas Pertencentes a Minorias Nacionais ou Étnicas, Religiosas e Linguísticas, adotada em 1992, às vésperas, portanto, da Conferência de Viena, insiste, no título e no artigo $1^{\circ}$, e de conformidade com o artigo 27 do Pacto Internacional de Direitos Civis e Políticos, que ela se dirige aos indivíduos delas participantes. Trata, portanto, nominal e tecnicamente, 
de direitos universais das pessoas integrantes de tais minorias. E são elas que conformam grupos vulneráveis de indivíduos discriminados, pessoal e coletivamente, num contexto que lhes é adverso.

Os direitos humanos são, por definição, de todos os seres humanos, que, em muitos casos, requerem tratamento especial para os titulares poderem deles usufruir. Nada impede - ao contrário tudo aconselha - que os Estados adotem políticas públicas em favor de segmentos populacionais que requeiram proteção particularizada. Conquanto os integrantes desses chamados grupos vulneráveis necessitem desse apoio, como pessoas e como grupos, seus direitos humanos, na acepção que lhes dava o sistema, decorrem da unversalidade imanente em tais direitos, inclusive o de participar da própria cultura, sendo esses titulares juridicamente iguais a todos os demais da família humana. Não porque sejam membros de uma cultura - repito cultura, em sentido etnográfico - diferente. Ressalto bem esse ponto porque uma das causas intrínsecas das dificuldades atuais do sistema internacional de promoção e proteção dos direitos humanos vem da confusão que ora se faz entre os direitos culturais da Declaração Universal e os hoje alardeados "direitos das culturas" e "direitos das minorias". Tais direitos não são previstos na Declaração Universal nem nos dois Pactos, que conformam, como tríade "constitucional", acima das demais normas, a "Carta Internacional dos Direitos Humanos", assim chamada por analogia com a Carta das Nações Unidas. Definidos em outros documentos, que não rejeito nem pretendo denegar, tais direitos podem ser importantes e certamente devem ser respeitados. Não podem, porém, ser integrados doutrinariamente à categoria superior dos "direitos humanos" na acepção original.

\section{DESVIOS POSTERIORES AO ACORDADO EM VIENA}

Os direitos culturais, previstos no artigo 27, Parágrafo $1^{\circ}$ da Declaração Universal, de 1948, refletidos no artigo 15 do Pacto de Direitos Econômicos, Sociais e Culturais, de 1966, são direitos do indivíduo, de participar livremente como pessoa - ou, como se dizia até recentemente, como sujeito autônomo -, sozinho ou em conjunto com os pares, "da vida cultural da comunidade, de fruir das artes e de participar dos benefícios do progresso científico e se seus benefícios". Não se trata de "direitos das culturas", supostamente superiores aos direitos de seus integrantes. Os direitos culturais das pessoas subentendem necessariamente a opção individual de se manter ou não na cultura de origem, de seguir ou não tradições, muitas das quais são discriminatórias. O direito civil à liberdade de religião, por exemplo, abordado em conjunto com a liberdade de pensamento e consciência nos documentos pertinentes, abrange a possibilidade de mudar de religião (artigo 18 da Declaração 
Universal $)^{7}$. Permite, portanto, a conversão voluntária e a opção de ser crente ou ateu; de observar ou recusar dogmas de qualquer tipo; de praticar ou não praticar os ritos e interditos de qualquer religião.

Assinalo que não tenho qualquer intenção de diminuir a importância das culturas e das diferenças étnicas, nem, muito menos, das diferenças decorrentes de sexo, gênero, orientação sexual, aptidão física ou deficiência. Elas são elementos úteis, às vezes essenciais, na configuração de políticas adequadas, para o gozo dos direitos universais e para a autoafirmação individual. Além disso, as diferenças enriquecem as sociedades contemporâneas, todas heterogêneas, formadas por influxos plurais. Seja como ingredientes que se misturam e se integram, malgrado as disparidades, numa comunidade maior, nacional, regional ou civilizacional, seja como elementos que não se fundem, mas convivem, as identidades são indissociáveis da personalidade humana. A não ser que se pretenda rejeitar a respectiva origem por motivos variados", o fato de se pertencer a uma ou mais "culturas", antropológicas ou ideológicas, pode e deve ser assumido, sem dar azo a discriminações. Não obstante, como que esquecendo os avanços de Viena, uma curiosa noção do politicamente correto foi-se impondo como camisa de força em favor das culturas ditas diferentes com direitos proprios. Incorporou-se em setores acadêmicos, daí se espalhando em movimentos sociais, militâncias, e contaminando partidos políticos e agentes estatais. Tornou-se de tal maneira dominante no discurso contemporâneo que qualquer observação a ele não acomodada é logo declarada sinal de intolerância.

Nesse contexto hegemônico dito "multiculturalista", quando alguém se coloca contra o cultivo de uma tradição iníqua, que obviamente agride direitos universais, corre o risco de ser tachado de racista ou machista, de não aceitar o "direito à diferença". Simpatizar com a proibição do véu ocultador de mulheres em países do Ocidente é visto como preconceito antimuçulmano e discriminação contra o "direito das mulheres" de se vestir como querem. Eu, cá por mim, gostaria de conhecer a opinião de Simone de Beauvoir sobre esse "direito" da mulher muçulmana! Ou de uma feminista e homossexual assumida, ainda atuante, como Camile Paglia! Universalista convicto, consciente de que "os direitos da mulher são direitos humanos" (artigo 14 da Declaração de Beijing), asserção que tenho orgulho de haver ajudado a garantir no documento final da Conferência de Beijing ${ }^{9}$, no entendimento de que

7 Note-se que, em 1948, essa foi uma das causas que levou a Arábia Saudita a abster-se, mas
não a se opor, quando da votação para a adoção da Declaração Universal na Assembleia Geral.
8 Para escapar a casamento forçado, mutilação genital ou perseguição a homossexuais, por exemplo.
9 Para quem supuser que essa frase, aparentemente tão óbvia, não pode haver enfrentado
dificuldades de aceitação, permito-me sugerir uma olhada no capítulo 7 de meu livro Relaçóes
Internacionais e Temas Sociais - A Década das Conferências (Brasília, FUNAG/IBRI, 2001,
p 211-244). Nele registro, com base na experiência como preparador e delegado, o que 
eles complementam a Declaração Universa ${ }^{10}$, prefiro sempre privilegiar a igualdade de todos, com as adaptações realmente necessárias. Assim como temo que os exageros em qualquer área sejam contraproducentes.

$\mathrm{O}$ "direito à diferença" como valor superior ao da igualdade programática, para a qual devem ser adotadas políticas eficazes, é modismo concebido no Ocidente para proteção de minorias não ocidentais contra o "eurocentrismo iluminista". Na prática atual, com obsessão reivindicatória de uns e ênfase paternalista de outros, ele legitima posições absurdas, como a defesa da burka na qualidade de direito, a adaptação de políticas sociais existentes para incorporar a poligamia da imigraçao, ou a aceitação conivente de estratificações por casta entre hindus na diáspora (que a Constituição da Índia há muito baniu oficialmente). Quando acomodada a esse extremo, ou politizada além do necessário, a diferença constitui um dos obstáculos mais insidiosos à proteção dos direitos universais. Convém lembrar, a propósito, que o discurso das diferenças tem utilidades e focos distintos. No Brasil, quando a imprensa fala em "diferença", refer-se em primeiro lugar aos homossexuais, que em culturas não ocidentais são criminalizados com base em religiões. Em segundo lugar vêm os negros. $\mathrm{Na}$ Europa, quando ativistas de direitos falam em "direito à diferença", o objeto prioritário é a comunidade de muçulmanos, imigrados e nacionais, discriminada e ressentida. Na maior parte da América hispânica, os ditos "diferentes" são os "índios". Nos Estados Unidos, os titulares seriam aparentemente todos os que não se enquadrem em modelos germânicos, nórdicos e anglo-saxões.

É um contrassenso equiparar os direitos humanos das pessoas discriminadas e perseguidas pela cor, por traços fenotípicos, origem herdada de nascença ou dos indígenas e quilombolas que vivem fora da sociedade por motivos não volitivos, com o "direito à diferença" de culturas que rejeitam esforços de integração não forçados. Quando abusivamente tratadas, os direitos humanos dessas pessoas, observados com medidas de proteção apropriadas, deveriam garantir-lhes a possibilidade de autoafirmação sem recorrer a um direito teórico. ${ }^{11}$

Em função do uso político da "diferença cultural", que a cultura

foram essas grandes conferências da última década do Século XX, inclusive os problemas causados pelas referências aos direitos da mulher. Com relação a essa afirmação de Beijing, foi necessário, para mantê-la, que eu declarasse em plenário que, sendo o Brasil a favor, não havia consenso contra no Grupo dos 77. Este pretendia apresentar a objeção de alguns como decisão de todos os países em desenvolvimento. Felizmente fui respaldado por diversas delegações, até então hesitantes.

10 Originalmente chamada Declaração Universal dos Direitos do Homem, cujas precedentes do Século XVIII, nos Estados Unidos e na França, de fato não incluíam as mulheres.

11 Ao escrever o original destas linhas, quando morava em Barcelona, soube que a Corte Europeia de Direitos Humanos havia determinado por sentença de $1^{\circ}$ de julho de 2014 para caso judicial a ela submetido, que a lei francesa de 2011, proibindo o uso de traje ocultador do rosto, não viola a liberdade de expressão da mulher muçulmana. Embora aprovada por 15 a 2, a sentença mostrava que, pelo menos nesse tribunal importante, a grande maioria dos juízes permanecia corajosamente imune aos absurdos impostos em nome do "politicamente correto". 
ou religião original nem exige ${ }^{12}$, e da reação que provoca na maioria quando ostentada de maneira panfletária, venho insistindo, no órgão de tratado de que sou membro, o CERD, que, assim como os países de destino devem respeitar as culturas dos imigrantes, os candidatos à emigração, ao solicitarem os vistos respectivos, devem comprometerse a observar os costumes dos países escolhidos. Não podem assumir um fundamentalismo alheio aos valores locais. O Comitê deveria, pois, nesses casos, fazer recomendações aos Estados de partida condizentes também com os de acolhida. Mas a militância dita "liberal" de colegas os leva a ignorar essa necessidade, encarando as culturas alheias como monólitos e tentando forçar as sociedades onde os imigrantes se instalam a aceitar práticas chocantes. Estas não se restringem à indumentária, nem a matérias do CERD. Sistemas previdenciários europeus têm sido induzidos por ativistas de direitos humanos a fornecer residências para as possíveis quatro esposas de muçulmanos procedentes de ex-colônias. As castas estendem interditos e prerrogativas em comunidades hindus na Grã-Bretanha. Até a mutilação genital feminina, que persiste em alguns grupos africanos na Europa, legitima-se pela oferta de serviços dessa espécie em unidades de saúde pública. Para evitar riscos maiores à saúde da menina, remedia-se o pior para não exigir o abandono de tradições. Viola-se, assim, claramente, o artigo $5^{\circ}$ da Declaração de Viena, um dos principais avanços. E se dá munição aos programas políticos anti-imigrantes.

Conforme já assinalei, não tenho qualquer dificuldade pessoal para a aceitação das diferenças culturais, nacionais, religiosas, de gênero, de preferência sexual ou outra que não violem direitos da pessoa humana. Todas podem e devem coexistir, tendo para protegêlas os direitos universais internacionalmente reconhecidos. Mas estou convicto de que, de forma mais ameaçadora para os direitos humanos do que os "valores asiáticos", ou simplesmete não ocidentais, o fundamentalismo politicamente correto fortalece as tendências racistas e ultranacionalistas que vêm ganhando terreno em eleições. Sem falar na justificativa que propiciam ao fundamentalismo religioso, tribal ou étnico dos "diferentes", opressivo e perigoso como o dos majoritários. Isto não significa que se devam descartar e deixar de combater as discriminações sofridas pelas pessoas e coletividades minoritárias. Elas são o primeiro fator que as induz à crispação defensiva.

Mencionei acima "valores asiáticos" porque muito se falou deles como ameaça aos direitos humanos na época da Conferência de Viena, em função das posições de delegações da Ásia contrárias à prioridade,

12 Estou cansado de confirmar com colegas de comitê e delegados muçulmanos na ONU que o uso de véu, inclusive o hijad que deixa o rosto visível, não é exigência religiosa, mas tradição pré-islâmica, limitada a regiões do Norte da África, Ásia Central e Oriente Próximo. Seu uso em países de imigração, conforme me diz clara e reiteradamente o colega argelino, com respaldo de correligionários subsaarianos, é político. 
senão exclusividade, conferida pelo Grupo Ocidental aos direitos civis e políticos. Entretanto, nenhuma delegação asiática, ou africana, rechaçou a ideia de direitos humanos per se, como se pensa em alguns círculos. A China, com razão inconteste, ainda que motivada pela política própria na matéria, em Viena recordou que os direitos humanos são resultado da história de cada país. Malásia e Cingapura assinalaram que, em seu entendimento, o coletivo é superior ao individual, tendo os cidadãos direitos e deveres perante a sociedade - tal como reconhece a Declaração Universal no artigo 29. Os países islâmicos tampouco negaram a noção universalista de direitos fundamentais de todos, procurando, ao contrário, reivindicar para a religião respectiva a origem de tais direitos. Os fundamentalismos extremados, que nunca foram particularmente afro-asiáticos, fortaleceram-se depois.

O que os delegados não integrantes do Grupo Ocidental de Estados, inclusive latino-americanos, buscaram com insistência em Viena foi o reconhecimento da igualdade, indivisibilidade e interdependência de todas as categorias de direitos universais, civis, políticos, econômicos, sociais e culturais, feito afinal obtido nos documentos. Quanto aos Estados asiáticos, o que justificadamente queriam e conseguiram em termos aceitáveis foi equilíbrio entre o universalismo dos direitos humanos e o particularismo dos diferentes sistemas político-culturais, que precisam ser levados em conta. E isso consta do artigo $5^{\circ}$ da Declaraçao de Viena, cujo texto vale a pena aqui repetir:

Todos os direitos humanos são universais, indivisíveis, inerdependentes e inter-relacionados. A comunidade internacional deve tratar os direitos humanos globalmente de forma justa e equitativa, em pé de igualdade e com a mesma ênfase. As particularidades nacionais e regionais devem ser levadas em consideração, assim como os diversos contextos históricos, culturais e religiosos, mas é dever dos Estados proteger todos os direitos humanos e liberdades fundamentais, independentemente de seus sistemas políticos, econômicos e culturais.

Criticado na época por ONGs internacionais do Ocidente como insuficiente. Insuficiente ele era quando mal lido, com olhos simplistas, unilaterais, eurocêntricos, que, contrariamente ao que afirmam, têm horror não assumido a esse reconhecido "direito à diferença".

\section{VIENA VÍTIMA DE SEU PRÓPRIO ÊXITO}

Enquantos muitos avanços de Viena foram distorcidos a posteriori, à sua revelia, há também complicadores do sistema a respeito dos quais é possível dizer que são consequência da Conferencia. Nesse sentido, Viena foi vítima de seu próprio êxito em 1993, tornando-se em médio 
prazo indutora de erros em decisões contrárias a seu "espirito"13.

Alguns desses complicadores provêm da amplitude ambiciosa dos campos para os quais a Conferência fez recomendações. Ao abrir o leque de atenções para todos os objetivos de ONGs e movimentos sociais com foco específico em grupos, Viena deu um sinal enganoso de que tudo poderia ser tratado no campo dos direitos humanos. Aí se incluíam recomendações sobre categorias populacionais cujas aspirações eram válidas, mas não se enquadravam nos direitos universais; para situações de guerra e conflagrações inter-étnicas, onde o sistema não tinha condições de atuar. Ao adotar um programa de ação muito extenso e pormenorizado, serviu de inspiração para uma produção excessiva de normas, que não passam de modelos pinçados, por órgãos sem mandato para isso. Daí, desses excessos de 1993, advém parte significativa da decepção geral com o tema, do irrealismo de que se burla a expressão francesa droits-de-l'hommisme (direito-humanismo) como sucedâneo da verdadeira política. Desprovida da intenção de promover o progesso social, a política se encontraria hoje reduzida, na melhor das hipóteses, à simples gestão da economia, contando com auxílio do multiculturalismo por justaposição, sem sincretismo ou miscigenação.

A verdade é que a Conferência de Viena, ao formular seu Programa de Ação para o sistema internacional de direitos humanos, não notou que outro sistema, mais concreto, adverso aos direitos humanos, estavase consolidando. Apresentado como "consenso de Washington", adotado e imposto pelo FMI e pelo Banco Mundial em prol da eficiência e da competitividade do Terceiro Mundo, esse sistema de economia neoliberal vinha exigindo a redução do Estado, com abandono de sua posição como provedor social. As reduções ou "ajustes estruturais" se faziam em todas as áreas, com cortes profundos de pessoal, privatizações dos setores mais sensíveis da economia e "desregulação" das finanças para o ingresso de capitais. Entrementes, na esfera da cultura, afirmavam-se as noções divisórias associadas à ideia de pós-modernidade. Enquanto Viena propunha ações que exigiam mais verbas e burocracias "weberianas" para atender às necessidades de muitos novos grupos titularizados com direitos especiais, o neoliberalismo econômico e o pós-modernismo multiculturalista se uniam contra o universalismo dos direitos humanos.

Os "cortes do excesso de gordura" 14 na carne do Estado não seriam capazes de impedir, a partir de 1998, a sequência de crises econômicas, no México, no Brasil, no Japão e nos "tigres asiáticos", continuadas depois por outras, nos próprios Estados Unidos e em países da Europa. Os "remédios", conforme previsível num sistema que rejeitava o chamado

13 O "espirito de Viena" foi expressão muito usada na década de 1990, inclusive em discursos do Secretário Geral das Nações Unidas, para estimular a flexibilização das posições dos Estados a fim de permitir o consenso nos textos em discussão.

14 Expressão muito comum na fase mais acirrada do "consenso de Washington". 
Estado Providência, idealizado por Keynes para salvar o capitalismo do crash de 1929, geravam desemprego maciço e sacrificavam sempre os pobres, em que se incluíam os grupos vulneráveis. Em lugar da esperada democracia política, o que se veio a implantar com a globalização econômica foi o "liberalismo" da eficiência, sem contrapesos ou pruridos de preocupação social. Dele participavam de maneira marcante as finanças especulativas, não produtivas, aplicadas e retiradas em função de interesses imediatos de lucro. Longe das liberdades e direitos fundamentais desejadas, o que se afirmava no planeta era uma liberdade econômica anitigualitária e não emancipatória. Quando funciona melhor, dá razão à lembrança de Angela Davis:

"No Norte global nós compramos a dor e a exploração de meninas do Sul global, que vestimos todos os dias em nossos corpos"15.

Tendo o mercado como único "valor" universal, qualquer esperança de ajuda ao desenvolvimento dos outros, qualquer instituição de segurança social, qualquer apoio aos direitos fundamentais de todos, especialmente na área econômica e social, eram vistos como empecilhos à produtividade. O mundo dos anos 1990 vivia um paradoxo: o apogeu do discurso dos direitos coincidia com a destruição de suas condições de realização. Viena programara iniciativas que exigiam mais Estado, enquanto o sistema econômico exigia Estado mínimo. Diante dessa contradição, a saída de um lado era a "terceirização", de outro o retalhamento do social por grupos de pressão específicos, deixando os direitos e a sobrevivência dos pobres ao assistencialismo da caridade possível.

Um paradoxo adicional persistente é que esses problemas, raramente analisados em conjunto, não impediram no período pósViena, nem impedem agora, com a Conferência Mundial de 1993 esquecida, a expansão contínua, exponencial, do sistema internacional de direitos humanos. Mas aí há outra questão relevante. Antes voltado para o progresso com liberdade de todos os seres humanos, o sistema foi passando a atuar para a satisfação de si próprio, tendo as ONGs defensoras de minorias e movimentos específicos da sociedade civil como força propulsora.

\section{A MULTIPLICAÇÃO DE NORMAS E MECANISMOS}

Para tentar melhorar a situação de certos grupos e categorias de pessoas, mencionados ou não nos documentos de Viena, o sistema de promoção e proteção dos direitos humanos passou a multiplicar normas cogentes e padrões de aplicação específicos, com novos mecanismos

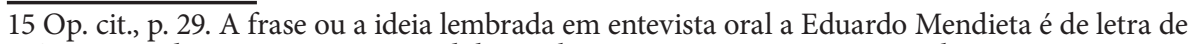
música cantada por Sweet Honey and the Rock. Cito-a porque me soa particularmente expressiva. 
de acompanhamento, inclusive para as recomendações dos órgãos de tratados. Tudo isso é prova de interesse, mas torna o conjunto demasiado complexo, frouxo, sem hierarquia, com elementos claramente conflitivos.

Não incluo nessa tendência que considero inadequada os novos tratados emanados de órgãos competentes do sistema, como a Convenção sobre os Direitos das Pessoas com Deficiências ou a Convenção sobre a Proteção contra Desaparecimentos Forçados, ambas de 2006, enquadradas em objetivos universalistas. Tampouco posso incluir propriamente a Convenção sobre os Direitos dos Trabalhadores Migrantes, que é de 1990, portanto anterior à Conferência de Viena de 1993 - embora ela somente tenha conseguido as vinte ratificações necessárias para sua entrada em vigor em 2003. Não posso deixar de observar, contudo, que, em contraste com o primeiro tratado de direitos humanos adotado na sequência da Declaração Universal de 1948, a Convenção sobre a Eliminação da Discriminação Racial, de 1965, tem 25 artigos, considerados suficientes até a Conferência de Durban de 2001, ao passo que a Convenção sobre um grupo em situação específica como os trabalhadores migrantes e suas famílias tem 93! Que o detalhamento de iniciativas e regras nas criações recentes do sistema é tamanho que as torna irrecordáveis, quase ilegíveis, além de, muitas vezes, inaplicáveis. Que o total de órgãos de tratados quando ocorreu a Conferência de Viena era de seis e hoje são mais de onze - alguns quais derivados de protocolos adicionais aos instrumentos principais. A esse número de instrumentos de escopo universalista, deve-se ainda adicionar o Convênio 169 da Organização Internacional do Trabalho (OIT) sobre Direitos dos Povos Indígenas e Tribais, dotado de seu próprio mecanismo de acompanhamento fora do sistema regular de direitos humanos.

O Convênio 169 da OIT, adotado em 1989 e em vigor desde 1991, constitui um caso sui generis por diversos aspectos. Sua forma e sua substância são as de um tratado de direitos abrangente, equivalente aos dois Pactos de 1966 reunidos, voltado exclusivamente para uma categoria de pessoas, os indígenas. A par disso, o Convênio reconhece também direitos coletivos, dos respectivos povos, que outras categorias não têm, como o direito às terras ancestrais. Não negociado, nem adotado pelos órgãos do sistema com competência na matéria, cujos Estados integrantes relutavam em emitir uma simples declaração sobre os direitos dessa categoria populacional em função de conceitos heterodoxos previstos ${ }^{16}$, o Convênio, que os inclui, com seu comitê de acompanhamento na própria OIT, emerge de uma organização

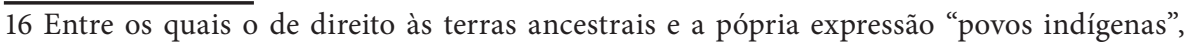
numa época em que "povo" era o conjunto da cidadania. Além disso, os povos eram, a rigor, desde os dois Pactos de 1966, titulares do direito coletivo à autodeterminação, voltado contra as metrópoles colonizadoras e o "neocolonialismo imperialista" das empresas capitalistas no Terceiro Mundo. 
especializada em direitos trabalhistas. Não obstante, depois de 2007, quando a Assembleia Geral das Nações Unidas adotou, com poucos votos negativos, a Declaração sobre os Direitos dos Povos Indígenas, o Convênio da OIT tem sido assimilado no sistema regular de direitos humanos. Passou ser usado como referência para cobranças pelo CERD sempre que se examinam comunicações e relatórios de Estados que tenham povos autoconsiderados "autóctones", não indígenas como nas Américas, em seu território.

Ao mesmo tempo em que se incrementou o número de convenções e órgãos de tratado no Direito Internacional dos Direito Humanos, aumentou enormemente a quantidade de comitês e grupos de trabalho para observação de temas e recomendação de novas regras. Enquanto em 1989, ano de convocação da Conferência de Viena, havia, como já visto, não mais de seis "relatores temáticos", em 2014 eles são trinta e já chegaram a ser mais de quarenta em outras ocasiões! O número dos "relatores de situações", de países escolhidos com seletividade agora mais chocante - por motivos que abordarei no próximo item -, para atender a uma aparente opinião pública forjada com rapidez e superficialidade pelas redes sociais, ou pela atuação de ONGS maximalistas, varia conforme o ano, sendo oito em 2014.

Ademais de tudo isso significar um crescimento exponencial de instrumentos de regulação e pressão sobre os Estados, a requerer mais verbas do orçamento regular da $\mathrm{ONU}^{17}$ e dos Estados, também constitui um aumento desmesurado de trabalho para os operadores domésticos de direitos humanos e para as funções de assessoramento do Secretariado das Nações Unidas. Como o fenômeno ocorre dentro de um sistema econômico com predomínio da ideia de "Estado mínimo", cujo pessoal burocrático não aumenta, diminui, a "solução natural" é também "terceirizar" e "privatizar" o sistema. Por mais que Viena tenha propiciado um incremento orçamentário importante para o verbete "direitos humanos" na ONU, em virtude da criação da figura do Alto Comissário em 1993, as verbas nunca são suficientes. Recorre-se então a contribuições adicionais voluntárias de Estados prósperos para projetos específicos, ou financiamentos privados de Fundações, para acompanhar a expansão dos serviços. A burocracia de funcionários internacionais "de carreira" na área, por sua vez, passa a ser complementada, ou substituída, por estagiários não remunerados, quase sempre estudantes de pós-graduação formados dentro de modismos da academia e dos meios de comunicação impressa e eletônica, seriamente interessados e politicamente corretos, mas sem experiência pregressa na defesa do universalismo dos direitos.

17 Para dar somente uma ideia, o número de peritos em órgãos de tratados, que necessitam de passagens e diárias para as sessões de trabalho - não remunerado - em Genebra, pelos menos duas vezes por ano, passou de 40 nos anos 1990 para 140 em 2014. 
É inegável que a proliferação de normas, mecanismos e tribunais não é exclusividade da área dos direitos humanos. Reprovada por juízes da Corte Internacional de Justiça, em função da criação de tribunais internacionais ad hoc e outros, a multiplicação de normas e sistemas já foi objeto de estudo aprofundado pela Comissão de Direito Internacional das Nações Unidas, na primeira década deste século. O tema tinha título eloquente: Fragmentação do Direito Internacional - Dificuldades Decorrentes da Diversificação e Expansão do Direito Internacional. O relatório final, de $2006^{18}$, coordenado pelo jurista finlandês Martti Koskenniemi, não chega a endossar a visão negativa que muitos têm do fenômeno Por outro lado, por mais que Koskenniemi tenha encarado tal fragmentação como decorrência natural da passagem de uma fase moderna, hierárquica, para a fase pós-moderna, horizontal, em que predominariam, em sua visão otimista, políticas de pluralismo, ele próprio recorda e cita autores segundo os quais a vocação do Direito é para a "ordem unificada e hieraquizada, unificada porque hieraquizada", sem a qual ele se torna ineficaz ${ }^{19}$. De minha parte, sem necessidade de maiores elucubrações, minhas preocupações, sempre voltadas para a área dos direitos humanos, são de dois tipos: uma doutrinária, que se reflete no real; a outra, somente pragmática.

A preocupação doutrinária é fácil de explicar: sendo os direitos humanos universais por definição, os direitos específicos de grupos culturais particularizados não podem ser classificados na mesma categoria. São "humanos" porque seus detentores também são pessoas físicas ou grupos delas, mas a titularidade advém da identidade étnica diferencial, não de predicados comuns a todas. Como já diziam Koskenniemi e Leino em 2002:

o liberalismo e a globalização não trouxeram coerência, muito pelo contrário. A estrutura suprida pela confrontação Leste-Oeste foi substituída por uma realidade de caleidoscópio, em que atores em competição lutavam para criar sistemas normativos competitivos entre si, frequentemente para escapar, de forma expressa, às limitações do direito diplomático - embora talvez, mais frequentemente, com uma ignorância deleitosa a seu respeito" 20 .

A preocupação de ordem pragmática que tenho é ainda mais evidente, conquanto raramente assumida e registrada. Com um número sempre ascendente de normas específicas, obrigações a cumprir e

18 United Nations' International Law Commission, Fragmentation of International Law: Difficulties Arising Form the Diversification and Expansion of International Law, Report of the study group, finalized by Martti Koskenniemi, documento A/CN.4/L. 682, 13 April 2006. 19 M. Delmas-Marty, Trois défis pour un droit mondial, Paris, Seuil, 1998, apud M.Koskenniemi \& Paivi Leino, "Fragmentation of International Law? Postmodern anxieties", 15 Leiden Journal of International Law, 2002, pp. 553-579 (minha tradução).

20 Op. cit., p 559. (minha tradução). 
relatórios a apresentar, que extrapolam as capacidades respectivas, nenhum Estado democrático bem intencionado consegue hoje estar em dia com os compromissos internacionais na matéria. Seus funcionários competentes não podem cumprir a contento sequer a obrigação de submeter informes tempestivos aos mecanismos de controle. Nem, muito menos, promover, na esfera doméstica, a aplicação das recomendações deles recebidas.

\section{OMISSÕES PROBLEMÁTICAS E REFORMA DO ÓRGÃO PRINCIPAL}

À proliferação exagerada de normas e cobranças irrealistas, numa fase em que o Estado é visto com desconfiança, devem-se acrescentar dificuldades de outra ordem, que fragilizam ainda mais o sistema, subtraindo seriedade às decisões que toma. Elas resultam de insuficiências internas antigas, que hoje se encontram particularmente visíveis, assim como de inversões de posturas desconcertantes, antes inimagináveis.

Ninguém em sã consciência pode ter dúvidas do horror que representou para os Estados Unidos e quase todo o mundo a destruição das torres do World Trade Center, em Nova York, em 11 de setembro de 2001. Poucos porão em dúvida a necessidade de medidas de prevenção ao terrorismo, particularmente em países considerados alvos preferenciais de um certo tipo de extremismo. Alguns políticos e intérpretes podem até justificar os bombardeios por alguns Estados, liderados por Washington, aos talibãs radicais do Afeganistão, por mais que tenham sido os Estados Unidos que primeiramente armaram esses "estudantes" corânicos, quando resistiam aos soviéticos na década de 1980. A invasão daquele país em fins de 2001 poderia até soar compreensível, não como retaliação pelos atentados em Nova York e Washington, perpetrados por outros "jihadistas", mas porque o território afegão oferecia abrigo e campos de treinamento aos terroristas do El Qaeda. Diferentemente do caso do Afeganistão, poucos defensores reais de direitos humanos poderiam haver aprovado a invasão ilegal do Iraque pelos Estados Unidos e seus aliados, em 2002, a partir de pretextos inconvincentes. Seguramente ninguém que defendesse os direitos humanos poderia aceitar, em qualquer circunstância, as torturas e tratamentos degradantes infligidos aos prisioneiros em quarteis e prisões americanas em Guantánamo, Al Ghraib, Baghram e outras. Não obstante, nenhuma resolução condenatória, nenhuma reprovação formal pelo sistema de proteção aos direitos humanos foi adotada.

Conquanto se possa dizer que a seletividade das situações escolhidas para relatorias sempre foi uma característica, a omissão deliberada perante violações conhecidas - algumas autofotografadas 
com sorrisos - nesse caso revelou-se especialmente negativa, com ares de conivência. Os Estados Unidos sempre se haviam apresentado como paladinos dos direitos humanos no mundo. O mesmo pode ser dito dos membros da União Europeia que, se não chegaram a torturar diretamente, enviaram indivíduos considerados suspeitos de terrorismo - muitos dos quais se comprovaram inocentes - para serem "interrogados de maneira forte" em território de terceiros ${ }^{21}$. Em lugar de uma condenação, ainda que meramente simbólica, para violações tão metódicas amplamente conhecidas, o que ocorreu no sistema internacional de direitos humanos foi a reforma de seu órgão principal!

É fato que muitos Estados e ONGs vinham pleiteando uma reforma do sistema havia anos. Sua preocupação principal era evitar a participação de Estados com regimes considerados violadores contumazes. Mas a reforma, afinal realizada para acomodar pressões dos Estados Unidos e da Europa, foi irrisória, senão contraproducente. A velha e historicamente produtiva Comissão dos Direitos Humanos das Nações Unidas, subordinada ao Conselho Econômico e Social (ECOSOC), que se reunia anualmente por 45 dias, foi transformada em Conselho de Direitos Humanos, não mais vinculado ao ECOSOC, como previa a Carta de 1945, mas diretamente à Assembleia Geral.

Com hieraquia elevada e título imponente, o novo Conselho conta com um também novo mecanismo, não seletivo, para apreciação da situação dos países: os Relatórios Periódicos Universais, que todos os Estados lhe apresentam. A par dessa inovação, certamente interessante, o Conselho, com sessões quase permanentes, segue estabelecendo uma profusão de relatores temáticos e grupos de trabalho, cujos informes são tantos que mal são lidos; procura atuar, sem resultados, sobre todos os conflitos armados importantes; organiza reuniões de alto nível em que Ministros de Estado apresentam suas políticas ao mundo; acolhe um número infinito de ONGs que falam para seus próprios públicos; abole intervalos para almoço a fim de acomodar uma infinidade de oradores em sessões intermináveis e confusas; atrai menos atenção da imprensa e do que a velha Comissão, mais enxuta, e sem telecomunicações eletrônicas imediatas, conseguia.

Em paralelo a tudo isso, dentro e fora do sistema, outros fatores da atualidade o enfraquecem. Todos os Estados e pessoas conscientes temem os assaltos criminosos os sequestros variados, o terrorismo

21 Pouco depois de redigir o original destas linhas, a Corte Europeia de Direitos Humanos condenou a Polônia por haver abrigado uma prisão secreta da CIA. Em veredito de 24 de de julho de 2014, os sete integrantes do Tribunal de Estrasburgo, entre os quais um juiz polonês, declararam que, além de deixar de proteger os direitos humanos de dois indivíduos árabes, um iemenita e um saudita, a Polônia havia colaborado com a CIA no envio de ambos para a prisão americana em Guantánamo, onde se encontravam até então. A sentença obrigou o Estado polonês a pagar indenizações aos dois prisioneiros. Vê-se,assim, que, enquanto o sistema internacional se omitia, e a Europa passava por tensões como havia muito não se viam, pelo menos a Corte Europeia de Direitos Humanos seguia cumprindo sua missão corretamente. 
suicida, fenômenos tão agravados no presente que parece haveremse tornado típicos da época. Consequentemente aceitam mecanismos contra eles que invadem sua privacidade. Isso ocorre tanto nas lojas, como nas ruas, nos prédios, em qualquer lugar. Abragem desde gravações em vídeo à espionagem profissional das comunicações por computadores e celulares "inteligentes", inclusive de autoridades políticas aliadas. Antes típicos de ditaduras e regimes totalitários, hoje essas práticas são vistas como normais e correntes. Embora contrárias ao direito à privacidade de cidadãos e não cidadãos, dentro e fora das fronteiras, somente engendram sinais de repulsa quando praticadas sem razão em comunicações de aliados, ou feitas e detectadas por adversários estratégicos.

A verdade é que hoje a cultura globalizada não se incomoda com bisbilhotices. Ao contrário, estimula o exibicionismo, inclusive de terroristas, facilitado pelos media eletrônicos em rede. Sem a certeza da divulgação mundial de seus atos mais chocantes, talvez o extremismo obtivesse menos seguidores. O segredo das vidas privadas é que passou a ser pernicioso, geralmente suspeito, sendo a gravação dissimulada de qualquer troca de mensagens o instrumento de acusação e meio de prova mais usado. Como se lê em muitas partes, como advertência sarcástica para todos: "sorria, você está sendo filmado".

Talvez essas inversões sejam úteis, com algum efeito preventivo. Nem por isso o crime organizado diminui, ou o terrorismo religioso deixa de perpetrar seus massacres, filmados pelas vítimas e difundidos no ato de execução. Delas, como do terror religioso, o sistema atual de direitos humanos, quando fala, fala pouco.

\section{AS ONGS E MOVIMENTOS SOCIAIS}

As conferências da década de 1990 foram os primeiros foros internacionais que se abriram às organizações não governamentais e movimentos sociais como representantes da sociedade civil. Iniciada em eventos paralelos na Rio-92 e em Viena, a participação crescente e crescentemente influente desses novos atores já estava consolidada no final do Século XX. Se não em pé de igualdade com os Estados, como atores que precisavam ser ouvidos. As ONGs se afiguravam desde então como alternativa ao esvaziamento do Estado como insituição eficaz para proteger o meio ambiente e promover os direitos humanos. O que se intuía levemente como aspecto de controle difícil era já a tendência a sua proliferação infinita.

Antes apresentadas como consciência ética organizada da sociedade civil, há ainda ONGS e outras entidades congêneres que acreditam nos direitos humanos como instrumento para conseguir avanços sociais. Seu foco é, porém, quase sempre, centralizado em minorias específicas. Poucas são universalistas, como as principais da 
época da Conferência de Viena ou os movimentos sociais do passado. Esvaziadas as primeiras pela multiplicação excessiva e desaparecidos os segundos, ligados a lutas de classes vistas como superadas, até mesmo organizações respeitáveis, eficientes em décadas passadas, demonstram hoje o mesmo tipo de defeito: um anacronismo de métodos junto a democracias transparentes que, longe de embaraçar os governantes visados, atrapalham as melhores intenções.

Da mesma maneira que o sistema de proteção aos direitos humanos nas Nações Unidas, praticamente todas as organizações não governamentais atuantes dentro dele foram treinadas para fazer denúncias contra regimes arbitrários, não para ajudar democracias a consolidar direitos. Com base em posições hoje obsoletas, insistem em condenar os Estados como se fossem naturalmente maus. Atuam, com relação a governos eleitos como partidos comuns de oposição em campanha. Algumas propõem realizações impossíveis nas condições existentes. Condenam qualquer ação policial, em vez de orientar as forças da ordem em suas funções legítimas, de proteger a sociedade contra o crime. Parecem esquecer, com maximalismo simplista, que, uma vez ultrassada a propaganda da "segurança nacional" para encobrir agressões à cidadania, a segurança de todos, juntamente com a vida e a liberdade de cada um, é o primeiro direito consagrado na Declaração Universal de 1948. Não notam que, enquanto no passado a proteção exigida pelos direitos humanos era contra o Estado, nas democracias existentes os cidadãos requerem a força do Estado de Direito, parcial ou totalmente perdida para a criminalidade imperante.

Em 2012 o Representante Regional para a América do Sul do Alto Comissariado das Nações Unidas para os Direitos Humanos, Amerigo Incalcaterra, já assinalava:

Em vários países da região, o Estado vai perdendo o monopólio do uso da força e frequentemente em parte de seu território já não é quem impõe a lei. São os bandos de criminosos, o narcotráfico, as gangues juvenis ou "maras", que desafiam a autoridade do Estado e impõem a lei do mais forte em detrimento do Estado de Direito. (...) A pobreza e a exclusão acrescentam uma dimensão e complexidade maior ao fenômeno, sendo os jovens das áreas urbanas pobres e marginalizadas o setor da população com maior propensão a serem as vítimas, e também os autores, das atividades criminosas" 22 .

Na verdade, pouco se conhece dos esforços governamentais mais sérios na área da segurança que não sejam os habituais reforços de

22 Prólogo do Escritório Regional para a América do Sul do Alto Comissariado das Nações Unidas para os Direitos Humanos (ACNUDH) ao documento "Produção e gestão de informação e conhecimento no campo da segurança cidadã: os casos da Argentina, Brasil, Paraguai e Uruguai”, Nações Unidas e IPPDH/ MERCOSUL, 2012. 
policiamento, sempre insuficiente, ou o recurso às forças armadas para manutenção da ordem ${ }^{23}$. Ainda que sejam conhecidos os trabalhos de instituições, autoridades e ONGs com políticas públicas para melhorar a situação de crianças e idosos, para atender às necessidades de pessoas com deficiências, à promoção social de comunidades carentes, o público acossado em seu cotidiano não nota que essas são atividades desenvolvidas para o conjunto da cidadania com base nos direitos humanos. Por outro lado, eu próprio vejo, na imprensa, no CERD e em foros correlatos, que a tendência predominante do sistema internacional de direitos humanos na fase contemporânea é de privilegiar minorias em detrimento das atenções para o conjunto. Pouca atenção é dada aos direitos das camadas gigantescas de pobres sem etnia ou outro elemento diferencial que as destaque. Para o neoliberalismo econômico e o "liberalismo" politico e cultural hegemônico, os simplesmente pobres são marginalizados porque fora do mercado, responsabilizados pela própria pobreza num círculo vicioso que só pode levar ao crime.

\section{QUE FAZER?}

Diante desse quadro desalentador, a pergunta necessária seria: o que fazer para melhorar essa situação negativa em que se atolou o sistema? A resposta, evidentemente, não é fácil. O primeiro passo, contudo, sempre consistirá na conscientização dos defeitos, com vontade de superá-los. Os problemas internos poderiam ser corrigidos com determinação volitiva dos atores. Os direitos humanos, contudo, não podem existir isolados.

Apesar de sua asserção como tema global nos anos 1990, hoje praticamente esquecida, a concretização dos direitos humanos se apresenta tão distante da realidade do Século XXI que quase se justificaria indagar se não era melhor para eles a situação da Guerra Fria. Se não seria melhor deixar de lado o discurso altaneiro da virada do milênio para começar a redefinir os direitos fundamentais de todos. Eles, afinal, são construções históricas. Se não o fossem, não haveria explicação para a situação variável do direito fundamental à propriedade, incluído na lista de 1948, expurgado, depois, dos dois Pactos de 1966, e reafirmado em resoluções quando o Comitê dos Direitos Humanos, do Pacto de Direitos Civis e Políticos, explicitou que a propriedade pode ser também comunal e coletiva. Talvez deixando um pouco de lado o discurso

23 Conquanto posterior ao momento de elaboração deste artigo e anterior a minha presente gestão, não posso omitir aqui um esforço de divulgação, limitado mas importante, realizado pelo Instituto de Politicas Públicas de Direitos Humanos do MERCOSUL com apoio do Escritório Regional para a America do Sul do Alto Comissariado das Nacoes Unidas para os Direitos Humanos, do PNUD e da Secretaria de Direitos Humanos do Brasil, ao elaborar e publicar a pesquisa Avances en la prevención y sanción de la tortura em los países del MERCOSUR (Buenos Aies, IPPDH, 2016). 
maximalista sobre minorias, cujas necessidades especiais devem ser respeitadas, mas não criam direitos universalizáveis para todos, daí se pudesse reconstruir o sistema com elementos adequados.

Quaisquer que venham a ser a forma e o conteúdo de tais direitos de todos os seres humanos, possivelmente repescados da Declaração de 1948 para retirada de escamas e modificações na receita de aplicação, eles precisarão estar coordenados com a economia. Pela via menos desejada, mudanças estão ocorrendo. A economia hoje já deixou de ser neoliberal para assumir as características antissociais e antihumanas da tecnologia eletrônica avançada, planejadas para a criação de sistemas que dispensam mediadores e gastos com mão de obra. O Estado, por sua vez, voltou a ser necessário. Não para promover a justiça e a segurança de todos. Para proteger o poder dos poderosos, o aumento contínuo de riqueza concentrada, o consumo suntuário do $1 \%$ de superricos, modelo ideal dos $10 \%$ ainda relativamente abastados. Desempregados sem futuro e miseráveis sem saída não contam.

Sei que o que a criação de um novo sistema previsível nas circunstâncias atuais é onírica. Nosso mundo carece de vontade e de tempo, crescentemente destroçado pela mudança climática, pelas guerras, pelos fundamentalismos, pelos retrocessos e erros que se acentuam nos sistemas e subsistemas existentes.

Enquanto nada de concreto é tentado, nem sequer na esfera do discurso, minha ambição é modesta. Quando me perguntaram há pouco por que continuo membro de um órgão de tratado, minha resposta foi franca. Porque fui eleito, reeleito três vezes e ainda não terminei meu mandato. Porque o CERD teve papel importante na conscientização, hoje quase universal, de que a discriminação racial ou étnica é fenômeno planetário: não há sociedade imune, mas ele pode ser controlado. Porque os trabalhos do comitê foram úteis no combate às formas mais absurdas de discriminação racista. Porque, ciente dos defeitos, tenho a impressão, possivelmente ilusória, de que, estando presente, consigo, senão melhoras no sistema, algum "controle de danos" em recomendações aos Estados.

A par desses fatos pessoais e circunstanciais, continuo falando de direitos universais porque entendo que eles ainda são uma boa utopia diretiva. Continuo defendendo o conceito anacrônico dos direitos humanos de todos, porque, sem um mínimo de esperança, a situação mundial amedronta.

\section{RESUMO BIOGRÁFICO}

José Augusto Lindgren Alves é Secretário Executivo do Instituto de Políticas Públicas de Direitos Humanos do MERCOSUL, Buenos Aires. Membro do Comitê para a Eliminação da Discriminacao Racial (CERD/ONU), Genebra. Ex-Embaixador do Brasil em Sófia , Bulgária; 
Budapeste, Hungria e Sarajevo, Bósnia e Herzegovina. Ex-Cônsul Geral em São Francisco e Barcelona, primeiro Diretor Geral do Departamento de Direitos Humanos e Temas Sociais do Ministério das Relações Exteriores, Brasília. Autor dos livros Os Direitos Humanos como Tema Global e Os Direitos Humanos na Pós-Modernidade. 